\title{
Polymethacrylates with anthryl and carbazolyl groups prepared by atom transfer radical polymerization
}

\author{
Dorota Neugebauer ${ }^{1}$, Dominik Charasim² ${ }^{2}$ Andrzej Swinarew ${ }^{2}$, Andrzej Stolarzewicz ${ }^{2}$, Michał Krompiec ${ }^{3}$, \\ Henryk Janeczek ${ }^{4}$, Jurate Simokaitiene ${ }^{5}$ and Juozas V Gražulevičius ${ }^{5}$
}

\begin{abstract}
Monomers containing chromophore groups, that is, 9-anthrylmethyl methacrylate (AMA) and 2-(9-carbazolyl)ethyl methacrylate (CMA), were copolymerized with methyl methacrylate (MMA) using atom transfer radical polymerization (ATRP) conditions, resulting in two series of (co)polymers with various amounts of included chromophore units, namely P(MMA-co-AMA) (3-30 mol\%) and PAMA and P(MMA-co-CMA) (3-20 mol\%). The relative reactivity ratios of both comonomer pairs were determined using the Fineman-Ross method $\left(r_{\mathrm{MMA}}=1.19, r_{\mathrm{AMA}}=0.48\right.$ and $\left.r_{\mathrm{MMA}}=1.10, r_{\mathrm{CMA}}=0.77\right)$. Glass transition temperatures $\left(T_{\mathrm{g}} \mathrm{s}\right)$ of the polymers increased with the content of chromophore groups. A comparison of luminescence demonstrated more intense light emission by polymethacrylates with carbazolyl groups than by copolymers with anthryl groups. The wavelength of emitted light also differed in the range of blue-violet and blue-green fluorescence for carbazolyl and anthryl copolymers, respectively.
\end{abstract}

Polymer Journal (2011) 43, 448-454; doi:10.1038/pj.2011.10; published online 2 March 2011

Keywords: anthracene; ATRP; carbazole; luminescence; polymethacrylates

\section{INTRODUCTION}

Luminescent polymers that have the ability to emit light in response to a stimulus are known as smart polymers. These polymers can be used for fabricating light-emitting diodes, electrophotographic and photorefractive materials, as well as photoluminescent and electroluminescent devices. ${ }^{1}$ A proper design of the molecular structure of polymers with luminescence is required to tune the emission color in various regions of the visible spectrum. The parameters responsible for this effect are related to the types of chromophore groups, and their content and density of incorporation in the polymer chain. Particularly, carbazole- and anthracene-based polymers, belonging to a large family of luminescent macromolecules, have found increasing interest because of their numerous industrial applications, such as coatings, inks, adhesives and photolithography, as well as their use in the construction of electrical switching devices. ${ }^{2}$

Previously, copolymers containing carbazolyl groups were synthesized using various polymerization methods, such as the cationic photopolymerization of epoxy, ${ }^{3}$ oxetane ${ }^{4}$ and vinyl ether monomers (2-(9-carbazolyl)ethyl vinyl ether) $;^{5-7}$ anionic polymerization of oxiranes ([(9-carbazolyl)methyl] or [(9-carbazolyl)ethoxymethyl $]$ oxirane $)^{8}$ or methacrylates (2-(N-carbazolyl)ethyl methacrylate $)^{9}$ and free radical polymerization (FRP) of vinyl monomers $(N$-vinylcarbazole), ${ }^{10,11}$ including (meth)acrylates. ${ }^{12,13}$ The other luminescent copolymers with anthryl substituents were prepared by conventional FRP.
The copolymers of 9-anthryloxyhexyl methacrylate and $n$-butyl methacrylate irradiated with ultraviolet light led to changes in the chemical structure due to dimerization of the anthracene units. ${ }^{14,15}$ The copolymerization of methyl methacrylate (MMA) with 9-anthrylmethyl methacrylate (AMA), initiated by benzoyl peroxide and carried out in toluene at $100-105^{\circ} \mathrm{C}$ within $24 \mathrm{~h}$, resulted in a series of random copolymers. ${ }^{16,17}$ Studies have indicated that the viscosity and hardness of polymers increase up to $20 \%$ when $4 \%$ of anthryl groups are introduced into the chain. However, 'conventional' polymers are characterized by broad molecular weight distributions (usually $M_{w} / M_{n}>2$ ), indicating that polymeric chains are heterogeneous with various degrees of polymerization and cannot be well-defined. In addition, the mixture of various chain-length fractions influences the miscellaneous chemical and physical properties of copolymers.

Atom transfer radical polymerization (ATRP), ${ }^{18,19}$ one of the controlled methods of radical polymerization yielding well-defined polymers, was also used for the preparation of the copolymers of MMA and the fluorescent units of 7-nitrobenz-2-oxa-1,3-diazole $(0.5 \mathrm{~mol} \%)$ with the starting group of phthalic anhydride using copper(I) bromide $(\mathrm{CuBr}) / 4,4^{\prime}$-dinonyl-2,2'-bipyridine as the catalyst system and diphenyl ether at $90^{\circ} \mathrm{C} .{ }^{20}$ Another poly(methyl methacrylate) (PMMA) with one anthracene fluorescent unit placed in the middle of the polymer chain was synthesized using a chlorinecontaining anthracene derivative as the bifunctional initiator

${ }^{1}$ Faculty of Chemistry, Department of Physical Chemistry and Technology of Polymers, Silesian Technical University, Gliwice, Poland; ${ }^{2}$ nnstitute of Materials Science, University of Silesia, Katowice, Poland; ${ }^{3}$ Faculty of Mathematics, Physics and Chemistry, Institute of Chemistry, University of Silesia, Katowice, Poland; ${ }^{4}$ Centre of Polymer and Carbon Materials, Polish Academy of Sciences, Zabrze, Poland and ${ }^{5}$ Faculty of Chemical Technology, Kaunas University of Technology, Kaunas, Lithuania

Correspondence: Dr D Neugebauer, Faculty of Chemistry, Department of Physical Chemistry and Technology of Polymers, Silesian Technical University, M. Strzody 9, Gliwice 44-100, Poland.

E-mail: dorota.neugebauer@polsl.pl

Received 22 September 2010; revised 24 November 2010; accepted 27 December 2010; published online 2 March 2011 
in the presence of $\mathrm{CuCl} / 2,2^{\prime}$-bipyridine in toluene at $130{ }^{\circ} \mathrm{C} .{ }^{21}$ A more active bromine initiator/catalyst system with bifunctional 9,10-bis(1-bromoethylcarbalkoxymethyl)anthracene and $\mathrm{CuBr} / 4,4^{\prime}$ di- $n$-heptyl-2,2'-bipyridine was used for the polymerization of styrene at $110^{\circ} \mathrm{C} .{ }^{22}$ The synthesis of well-defined PMMA- $b$-poly(alkyl acrylate) diblock copolymers with a single fluorescent dye molecule (phenanthrene or anthracene) at the junction was also investigated. The anionic polymerization of methacrylate in tetrahydrofuran (THF) at $-78^{\circ} \mathrm{C}$, using the 3-(tert-butyldimethylsilyloxy)-1-propyllithium/1aryl-1-phenylethylene (aryl=2-phenanthryl or 2-anthryl) monoadduct as the initiator, in the next step after transformation of the anionic active site into a bromoester group was combined with ATRP of the alkyl acrylate. ${ }^{23}$

There are also reports of the synthesis of PMMA containing barely $1 \mathrm{~mol} \%$ of AMA units using ATRP. ${ }^{16}$ A reaction was performed for a comonomer proportion of 100:1 in the presence of a bromide initiator containing a di-tert-butyl phthalate functional group and a $\mathrm{CuBr} / 4,4^{\prime}$ dinonyl-2,2'-bipyridyne catalyst system with diphenyl ether at $90{ }^{\circ} \mathrm{C}$. These conditions provided a copolymer with a molecular weight of $12.8 \mathrm{~kg} \mathrm{~mol}^{-1}$ and a polydispersity index of 1.24 , in which one unit of the anthryl monomer was introduced into the polymer chain.

The aim of this work was to incorporate a larger fraction (10$60 \mathrm{wt} \%)$ of AMA or 2-(9-carbazolyl)ethyl methacrylate (CMA) into a polymer chain by copolymerization with MMA using ATRP conditions as a supplement to studies on luminescent polymers. The experiments were performed in nonpolar solvent at $70{ }^{\circ} \mathrm{C}$ in the presence of a $\mathrm{CuBr} / N, N, N^{\prime}, N^{\prime \prime}, N^{\prime \prime}$-pentamethyldiethyltriamine (PMDETA) catalyst system using a bromide initiator. Two series of luminescent polymethacrylates with various amounts of chromophore groups were successfully obtained with well-defined structures and a lower polydispersity index $\left(\mathrm{M}_{\mathrm{w}} / \mathrm{M}_{\mathrm{n}} \leqslant 1.5\right)$ compared with carbazoleand anthracene-based copolymers prepared by uncontrolled conventional FRP.

\section{MATERIALS AND METHODS}

\section{Materials}

Both CMA and AMA containing chromophore groups were obtained by esterification of methacryloyl chloride with 9-(2-hydroxyethyl)carbazole and 9-hydroxymethylanthracene. ${ }^{24,25}$ MMA (Sigma-Aldrich Chemicals Co., St Louis, MO, USA) was passed through an alumina column to remove the antioxidant inhibitor monomethyl ether hydroquinone (MEHQ). $\mathrm{CuBr}$ (Aldrich) was stirred with glacial acetic acid (Fisher Scientific, Schwerte, Germany) and then filtered, and the solid was washed three times with ethanol and twice with diethyl ether. The solid was dried under vacuum $\left(1 \times 10^{-2} \mathrm{mbar}\right)$ for 2 days. PMDETA (Aldrich), ethyl 2-bromoisobutyrate (EtBriBu, Aldrich) and all other solvents and internal standards were used without purification.

\section{Measurements}

Gel-permeation chromatography (GPC). The measurements were conducted in THF at $40^{\circ} \mathrm{C}$ with a flow rate of $1 \mathrm{ml} \mathrm{min}^{-1}$ using Shodex columns (KF-805L $300 \times 8.0 \mathrm{~mm}$ ) (Shodex Europe, Munich, Germany). The molecular weights and polydispersity indices of the copolymers were determined on the basis of linear PMMA standards.

${ }^{1} \mathrm{H}$ nuclear magnetic resonance $\left({ }^{1} H \mathrm{NMR}\right)$. The spectra were recorded on a Brüker DRX400 MHz spectrometer (Brüker, Rheinstetten, Germany) in chloroform- $d$ at room temperature.

Characterization of monomers. ${ }^{1} \mathrm{H}$ NMR AMA $\left(\mathrm{CDCl}_{3}\right)$ chemical shifts $\delta$ (p.p.m.) are given for the underlined hydrogen atoms: 8.52, 8.25, 7.96, 7.48 and $7.38(1 \mathrm{H}, 2 \mathrm{H}, 2 \mathrm{H}, 2 \mathrm{H}, 2 \mathrm{H}$, arom. $-\mathrm{CH}=), 6.35\left(1 \mathrm{H}, \mathrm{CHH}=\mathrm{C}\left(\mathrm{CH}_{3}\right)-\right)$, $5.85\left(2 \mathrm{H},-\mathrm{COO}-\mathrm{CH}_{2}-\mathrm{C}_{\mathrm{ANTH}}\right), 5.52\left(\overline{\mathrm{H}}, \mathrm{CHH}=\mathrm{C}\left(\mathrm{CH}_{3}\right)-\right), 1.93 \quad(3 \mathrm{H}$, $\left.\mathrm{CH}_{2}=\mathrm{C}\left(\mathrm{CH}_{3}\right)-\right) ;{ }^{1} \mathrm{H} \overline{\mathrm{N} M R} \mathrm{CMA}\left(\mathrm{CDCl}_{3}\right) \delta$ (p.p. $\overline{\mathrm{m}}$.): 8.05, 7.48, 7.25, 6.88

$(2 \mathrm{H}, 2 \mathrm{H}, 2 \mathrm{H}, 2 \mathrm{H}$, arom. $-\mathrm{CH}=), 5.88\left(1 \mathrm{H}, \mathrm{CHH}=\mathrm{C}\left(\mathrm{CH}_{3}\right)-\right), 5.45(1 \mathrm{H}$, $\left.\mathrm{CHH}=\mathrm{C}\left(\mathrm{CH}_{3}\right)-\right), 5.75\left(3 \mathrm{H}, \overline{\mathrm{CH}}_{2}=\mathrm{C}\left(\mathrm{CH}_{3}\right)-\right), 4.53\left(2 \mathrm{H},-\mathrm{COO}-\mathrm{CH}_{2}-\mathrm{CH}_{2}-\right.$ $\mathrm{O}-\overline{)}, 3.45\left(2 \mathrm{H},-\mathrm{O}-\mathrm{CH}_{2}-\mathrm{CH}_{2}-\mathrm{N}_{\mathrm{CARB}}\right) ;{ }^{1} \mathrm{H}$ NMR MMA $\left(\mathrm{CDCl}_{3}\right) \delta$ (p.p.m.): $6.11\left(1 \mathrm{H}, \mathrm{CHH}=\mathrm{C}\left(\mathrm{CH}_{3}\right)-\right), 5.53\left(1 \mathrm{H}, \mathrm{CH}-\underline{\mathrm{H}}=\mathrm{C}\left(\mathrm{CH}_{3}\right)-\right), 3.59\left(3 \mathrm{H},-\mathrm{O}-\mathrm{CH}_{3}\right)$, $1.95\left(3 \mathrm{H},=\overline{\mathrm{C}}\left(\mathrm{CH}_{3}\right)\right)$.

Thermal analysis. Differential scanning calorimetry (DSC) was performed using a TA-DSC 2010 calorimeter (TA Instruments, New Castle, DE, USA). Heating and cooling runs were performed at a rate of $20^{\circ} \mathrm{C}$ per min in the temperature range from -80 to $200^{\circ} \mathrm{C}$.

Luminescence. Absorption and emission spectra were recorded on a spectrofluorometer Fluoromax 4 (HORIBA Jobin-Yvon, Munich, Germany) equipped with a 450-W xenon lamp as a light source. The measurements were made at ambient temperature. Samples of the polymers were prepared in a THF solution with a concentration of $2 \times 10^{-6} \mathrm{moll}^{-1}$. The fluorescence detector was set for an emission wavelength of $295 \mathrm{~nm}$.

\section{Synthesis}

General procedure for ATRP of luminescent monomer with MMA. In a Schlenk flask, AMA (0.1 g; $0.36 \mathrm{mmol})$ was dissolved in MMA (1 ml; $9.4 \mathrm{mmol})$ and anisole $(0.2 \mathrm{ml})$. Once dissolved, PMDETA $(10.5 \mu \mathrm{l} ; 0.05 \mathrm{mmol})$ and $\mathrm{Cu}(\mathrm{I}) \mathrm{Br}$ $(7.0 \mathrm{mg} ; 0.05 \mathrm{mmol})$ were added under argon flow, and then the mixture was purged by an inert gas for $1 \mathrm{~h}$ to minimize oxygen contamination. The Schlenk flask with the reaction mixture was placed in a temperature-controlled oil bath at $70^{\circ} \mathrm{C}$, and after $1 \mathrm{~min}$, EtBriBu $(7.0 \mu \mathrm{l} ; 0.05 \mathrm{mmol})$ was added to start the reaction. The polymerization at a significantly higher viscosity of reaction mixture was stopped by exposing the solution to air. The solution was then diluted with chloroform and filtered through a column of activated (neutral) alumina to remove the copper catalyst. Finally, the polymers were precipitated in methanol and dried under vacuum at room temperature to a constant mass. A similar procedure was also used for the copolymerization of MMA with CMA.

${ }^{1} \mathrm{H}$ NMR P(MMA-co-AMA) $\left(\mathrm{CDCl}_{3}\right) \delta$ (p.p.m.): 0.5-1.2 (3H; $-\mathrm{CH}_{2}$ $\left.\mathrm{C}\left(\mathrm{CH}_{3}\right)-\right), 1.5-2.1\left(2 \mathrm{H} ;-\mathrm{CH}_{2}-\mathrm{C}\left(\mathrm{CH}_{3}\right)-\right), 3.3-3.6\left(3 \mathrm{H},-\mathrm{O}-\mathrm{CH}_{3}\right), 5.7-6.1$ $\left(2 \mathrm{H},-\mathrm{O}-\mathrm{CH}_{2}-\mathrm{C}_{\mathrm{ANTH}}\right), 7.3-8.6$ (9H, arom. $\left.-\mathrm{CH}=\right)$.

${ }^{1} \mathrm{H}$ NMR P(MMA-co-CMA) $\left(\mathrm{CDCl}_{3}\right) \delta$ (p.p.m.): $0.5-1.2\left(3 \mathrm{H} ;-\mathrm{CH}_{2}\right.$ $\left.\mathrm{C}\left(\mathrm{CH}_{3}\right)-\right), 1.5-2.1\left(2 \mathrm{H} ;-\mathrm{CH}_{2}-\mathrm{C}\left(\mathrm{CH}_{3}\right)-\right), 3.3-3.6\left(3 \mathrm{H},-\mathrm{O}-\mathrm{CH}_{3}\right), 4.32(2 \mathrm{H}$, $\left.-\mathrm{O}-\overline{\mathrm{C}} \mathrm{H}_{2}-\mathrm{CH}_{2}-\mathrm{N}_{\mathrm{CARB}}\right), 4.56\left(2 \mathrm{H},-\mathrm{O}-\mathrm{CH}_{2}-\mathrm{CH}_{2}-\mathrm{N}_{\mathrm{CARB}}\right), 7.1-\overline{8} .3$ (8H, arom. $-\mathrm{CH}=$ ).

\section{RESULTS AND DISCUSSION}

Two series of copolymers containing the chromophoric groups, anthryl and carbazolyl, were obtained by controlled ATRP (Scheme 1).
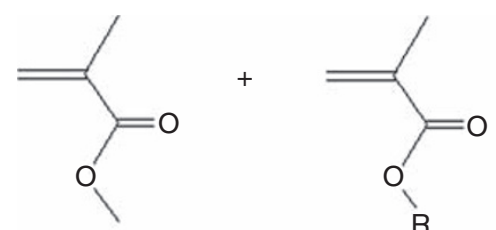

EtBriBu CUBr/PMDETA anisole, $70^{\circ} \mathrm{C}$

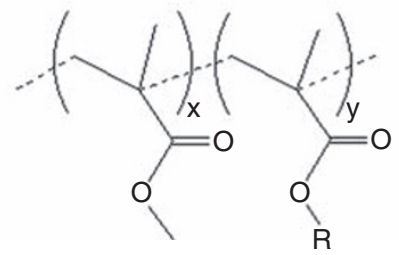

Scheme 1 Copolymerization of luminescent monomer with MMA by ATRP. ATRP, atom transfer radical polymerization; MMA, methyl methacrylate.<smiles>CCc1c2ccccc2cc2cc(C(C)(C)C)ccc12</smiles><smiles>CCCn1c2ccccc2c2ccccc21</smiles> 
Table 1 (Co)polymerization of AMA with MMA by ATRP

\begin{tabular}{|c|c|c|c|c|c|c|c|c|c|c|}
\hline \multirow[b]{2}{*}{ No. } & \multicolumn{2}{|c|}{$f_{1}^{\text {a }}$} & \multirow[b]{2}{*}{ Time (h) } & \multirow[b]{2}{*}{ Overall conversion $X$} & \multirow[b]{2}{*}{$D P_{n}^{\mathrm{b}}$} & \multirow[b]{2}{*}{$M_{n}^{\mathrm{c}}\left(\mathrm{g} \mathrm{mol}^{-1}\right)$} & \multirow[b]{2}{*}{$M_{w} / M_{n}^{c}$} & \multirow[b]{2}{*}{$F_{1}^{\mathrm{d}}(\mathrm{mol})$} & \multirow[b]{2}{*}{$T_{g}^{\mathrm{e}}\left({ }^{\circ} \mathrm{C}\right)$} & \multirow[b]{2}{*}{ Yield (\%) } \\
\hline & $w t$ & $\mathrm{~mol}$ & & & & & & & & \\
\hline II & 0.096 & 0.037 & 0.75 & 0.760 & 152 & 9200 & 1.28 & 0.030 & 110.3 & 76 \\
\hline III & 0.242 & 0.105 & 2.5 & 0.680 & 136 & 10800 & 1.31 & 0.088 & 114.0 & 68 \\
\hline IV & 0.390 & 0.187 & 24 & 0.771 & 154 & 10200 & 1.45 & 0.153 & - & 78 \\
\hline
\end{tabular}

Abbreviations: AMA, 9-anthrylmethyl methacrylate; ATRP, atom transfer radical polymerization; CuBr, copper(I) bromide; DSC, differential scanning calorimetry; EtBriBu, ethyl 2-bromoisobutyrate; GPC, gel-permeation chromatography; MMA, methyl methacrylate; NMR, nuclear magnetic resonance; PMDETA, $N, N, N^{\prime}, N^{\prime \prime}, N^{\prime \prime}-$ pentamethyldiethyltriamine; PMMA, poly(methyl methacrylate). Conditions: $[\mathrm{AMA}+\mathrm{MMA}]_{0} /[\mathrm{EtBriBu}]_{0} /[\mathrm{CuBr}]_{0} /[\mathrm{PMDETA}]_{0}=200 / 1 / 1 / 1$, anisole/AMA=2/1 (vol/wt), with the exception of $\mathrm{VI}: 1.5 / 1 ; T=70{ }^{\circ} \mathrm{C}$

anitial weight and molar feed fraction of AMA used for copolymerization;

${ }^{\mathrm{b}} \mathrm{DP}_{n}=\mathrm{X} \frac{\mathrm{AMA}+\mathrm{MMA}]_{0}}{[\mathrm{EtBriB} \psi}$, where: $\frac{[\mathrm{AMA}+\mathrm{MMA}]_{0}}{[\mathrm{G}}=200$.

"Measured by GPC in THF with PMMA standards.

${ }^{\mathrm{d} C}$ Copolymer fraction of AMA calculated by ${ }^{1} \mathrm{H}$ NMR: $F_{1}=\frac{I_{1} / 5 \mathrm{H}}{\left(I_{2} / 3 \mathrm{H}\right)+\left(I_{1} / 5 \mathrm{H}\right)}, F_{2}=1-F_{1}$, where $F_{1}$ and $F_{2}$ are the contents of AMA and MMA units, respectively, in the copolymer chain, $I_{1}$ the peak area of proton in $-\mathrm{CH}=(\delta=7.7-8.7$ p.p.m., $5 \times 1 \mathrm{H})$ characteristic for AMA units and $I_{2}$ the peak area of protons in $-0-\mathrm{CH}_{3}(\delta=3.3-3.7$ p.p.m., $3 \mathrm{H})$ for MMA units.

eDetermined by DSC during the second heating run.

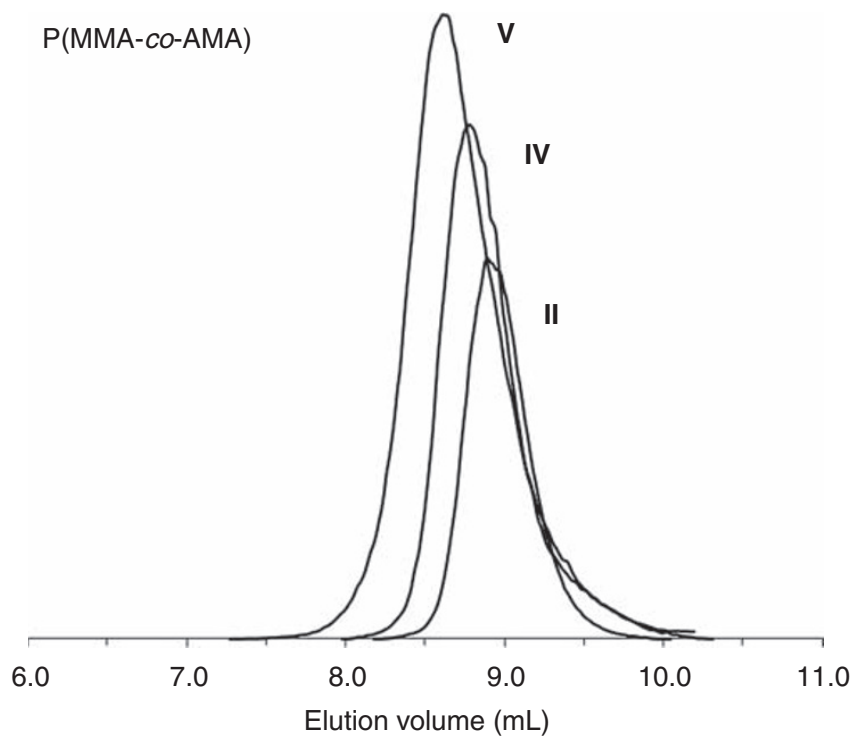

Figure 1 GPC traces of P(MMA-co-AMA) (II, IV and V). Conditions are given in Table 1. AMA, 9-anthrylmethyl methacrylate; GPC, gel-permeation chromatography; MMA, methyl methacrylate.

The copolymerization of MMA with various amounts of AMA (10-60 wt\%; 4-35 mol\%) was initiated by EtBriBu in the presence of a more active complex of CuBr/PMDETA with a small amount of anisole as a solvent at $70{ }^{\circ} \mathrm{C}$. The detailed data are presented in Table 1 . The polydispersity index value for copolymer II with the smallest AMA amount $(3 \mathrm{~mol} \%)$ was close to that observed for homopolymer PMMA I $\left(\mathrm{M}_{\mathrm{w}} / \mathrm{M}_{\mathrm{n}}\right.$ : $\left.\sim 1.27\right)$ synthesized under the same conditions. The increasing content of AMA units in the copolymers (III-V) resulted in an increase in the $\mathrm{M}_{\mathrm{n}}$ value, but $\mathrm{M}_{\mathrm{w}} / \mathrm{M}_{\mathrm{n}}$ also increased slightly to 1.45 at $15 \mathrm{~mol} \%$ of AMA content in the copolymer (IV), and at $28 \mathrm{~mol} \%$ of AMA (V), the value was much higher $\left(M_{w} / M_{n}>1.5\right)$. Higher polydispersities of AMA copolymers can be explained by the steric hindrance of the anthracene group consisting of three conjugated aromatic rings, which not only influence the slow propagating step but also provide an opportunity for the termination of growing chains. The GPC traces for these types of copolymers show monomodal signals, which are broadened with increasing AMA content (Figure 1). Moreover, the incorporation of

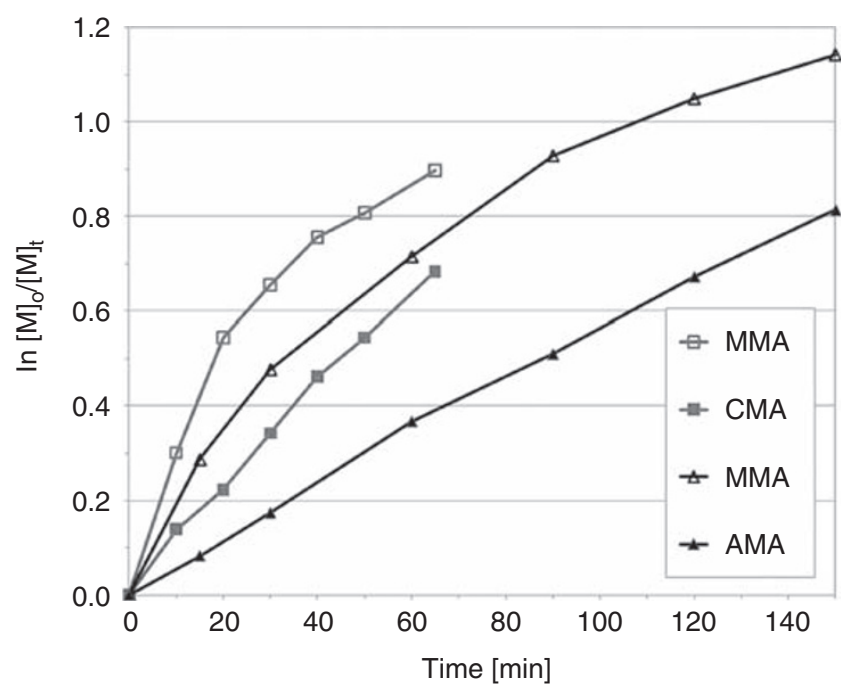

Figure 2 First-order plot of monomer consumption vs time for copolymerization of the following monomer pairs: MMA (empty triangles)/ AMA (full triangles) and MMA (empty squares)/CMA (full squares). Conditions for the copolymerization of MMA and AMA (III) are noted in Table 1, and those for the copolymerization of MMA and CMA (VIII) are noted in Table 2. AMA, 9-anthrylmethyl methacrylate; CMA, 2-(9-carbazolyl)ethyl methacrylate; MMA, methyl methacrylate.

larger amounts of AMA (IV and V) significantly extended the reaction time. Copolymerization kinetics revealed that MMA is consumed at a faster rate than AMA (Figure 2), and after $1 \mathrm{~h}$, the reaction reached $51.1 \%$ of MMA and $30.8 \%$ of AMA conversion. Lower reactivity of AMA was also the reason for choosing a more active system for the copolymerization of MMA/AMA, even though MMA is known as an 'easy polymerizing' monomer that does not need a highly activated catalyst system. For example, PMMA with values of $\mathrm{M}_{\mathrm{n}}=10.7 \mathrm{~kg} \mathrm{~mol}^{-1}$ and $\mathrm{M}_{\mathrm{w}} / \mathrm{M}_{\mathrm{n}}=1.13$ can be obtained within $2 \mathrm{~h}$ with $55 \%$ of monomer conversion using a less activated $\mathrm{CuBr} / 4,4^{\prime}$ dinonyl-2,2'-bipyridyne.

The rate of AMA homopolymerization was significantly reduced (VI). It was partially dependent on a large amount of solvent, which is required in the case of a solid monomer to obtain a well-stirred reaction mixture with optimal viscosity. Unfortunately, such conditions and the steric hindrance of the anthryl monomer extended the 
Table 2 Copolymerization of CMA with MMA by ATRP

\begin{tabular}{|c|c|c|c|c|c|c|c|c|c|c|}
\hline \multirow[b]{2}{*}{ No. } & \multicolumn{2}{|c|}{$F_{1}^{\mathrm{a}}$} & \multirow[b]{2}{*}{ Time (min) } & \multirow[b]{2}{*}{ Overall conversion $X$} & \multirow[b]{2}{*}{$D P_{n}^{\mathrm{b}}$} & \multirow[b]{2}{*}{$M_{n}^{\mathrm{c}}\left(\mathrm{g} \mathrm{mol}^{-1}\right)$} & \multirow[b]{2}{*}{$M_{w} / M_{n}^{\mathrm{c}}$} & \multirow[b]{2}{*}{$F_{1}^{\mathrm{d}}(\mathrm{mol})$} & \multirow[b]{2}{*}{$T_{g}^{\mathrm{e}}\left({ }^{\circ} \mathrm{C}\right)$} & \multirow[b]{2}{*}{ Yield (\%) } \\
\hline & Wt & $\mathrm{Mol}$ & & & & & & & & \\
\hline VIII & 0.242 & 0.105 & 65 & 0.609 & 122 & 15600 & 1.46 & 0.095 & 118.7 & 61 \\
\hline IX & 0.427 & 0.210 & 75 & 0.529 & 106 & 16200 & 1.53 & 0.189 & 125.0 & 53 \\
\hline
\end{tabular}

Abbreviations: ATRP, atom transfer radical polymerization; CuBr, copper(I) bromide; DSC, differential scanning calorimetry; EtBriBu, ethyl 2-bromoisobutyrate; GPC, gel-permeation chromatography; MMA, methyl methacrylate; NMR, nuclear magnetic resonance; PMDETA, $N, N, N^{\prime}, N^{\prime \prime}, N^{\prime \prime}$-pentamethyldiethyltriamine; PMMA, poly(methyl methacrylate).

Conditions: $[\mathrm{CMA}+\mathrm{MMA}]_{0} /[\mathrm{EtBriBu}]_{0} /[\mathrm{CuBr}]_{0} /[\mathrm{PMDETA}]_{0}=200 / 1 / 1 / 1$, anisole/CMA $=1 / 1$ (vol/wt), $T=70^{\circ} \mathrm{C}$

anitial weight and molar feed fraction of CMA are used for copolymerization.

${ }^{\mathrm{b}} \mathrm{DP}_{n}=\mathrm{X} \frac{[\mathrm{CMA}+\mathrm{MMA}]_{0}}{[\mathrm{EtBriBu}]_{0}}$, where $\frac{[\mathrm{CMA}+\mathrm{MMA}]_{0}}{[\mathrm{EtBriBu}]_{0}}=200$.

'Measured by GPC in THF with PMMA standards.

${ }^{\mathrm{d}}$ Copolymer fraction of CMA is calculated by ${ }^{1} \mathrm{H}$ NMR: $F_{1}=\frac{I_{1} / 4 \mathrm{H}}{{ }^{2}}, F_{2}=1-F_{1}$, where $F_{1}$ and $F_{2}$ are the contents of CMA and MMA units, respectively, in the copolymer chain, respectively, $l_{1}$ the peak area of protons in $-0-C_{2}-C_{2}-N_{A r}(\delta=4.0-4.7$ p.p.m., $4 \mathrm{H})$ characteristic for CMA units and $I_{2}$ the peak area of protons in $-0-\mathrm{CH}_{3}(\delta=3.3-3.7$ p.p.m., $3 \mathrm{H})$ for MMA units. eDetermined by DSC during the second heating run.

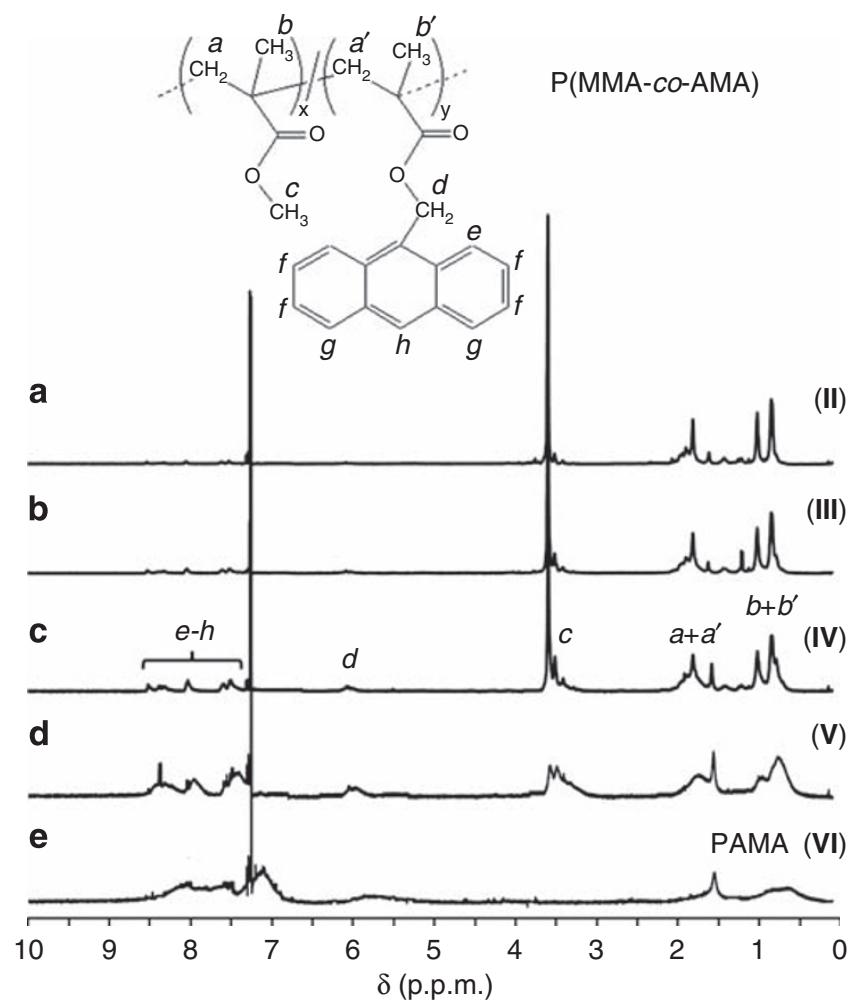

Figure $3{ }^{1} \mathrm{H}$ NMR spectra of (a-d) P(MMA-co-AMA) (II-V) and (e) PAMA (VI). Conditions are given in Table 1. AMA, 9-anthrylmethyl methacrylate; MMA, methyl methacrylate; NMR, nuclear magnetic resonance.

reaction time with the loss of process control. The resulting polymer was characterized by broad molecular weight distribution $\left(M_{w} / M_{n}\right.$ $\sim 1.7$ ) that indicates poorly controlled polymerization, with occurrences of chain-terminating side reactions in greater amounts than expected.

Similar copolymerization conditions (EtBriBu/CuBr/PMDETA) were applied to MMA and CMA comonomer pairs with various initial ratios of 90/10, 76/24 and 57/43 wt\% (96/4, 90/10 and 79/ $21 \mathrm{~mol} \%$, respectively) resulting in a series of copolymers (VII-IX) with differential distributions of carbazolyl substituents (Table 2, Scheme 1). In the case of representative sample VIII, the semilogarithmic dependence of monomer consumption on time shows slightly higher values for MMA than for CMA (Figure 2); for example, the conversions $59.2 \%$ of MMA and $49.5 \%$ of CMA were reached within $1 \mathrm{~h}$.

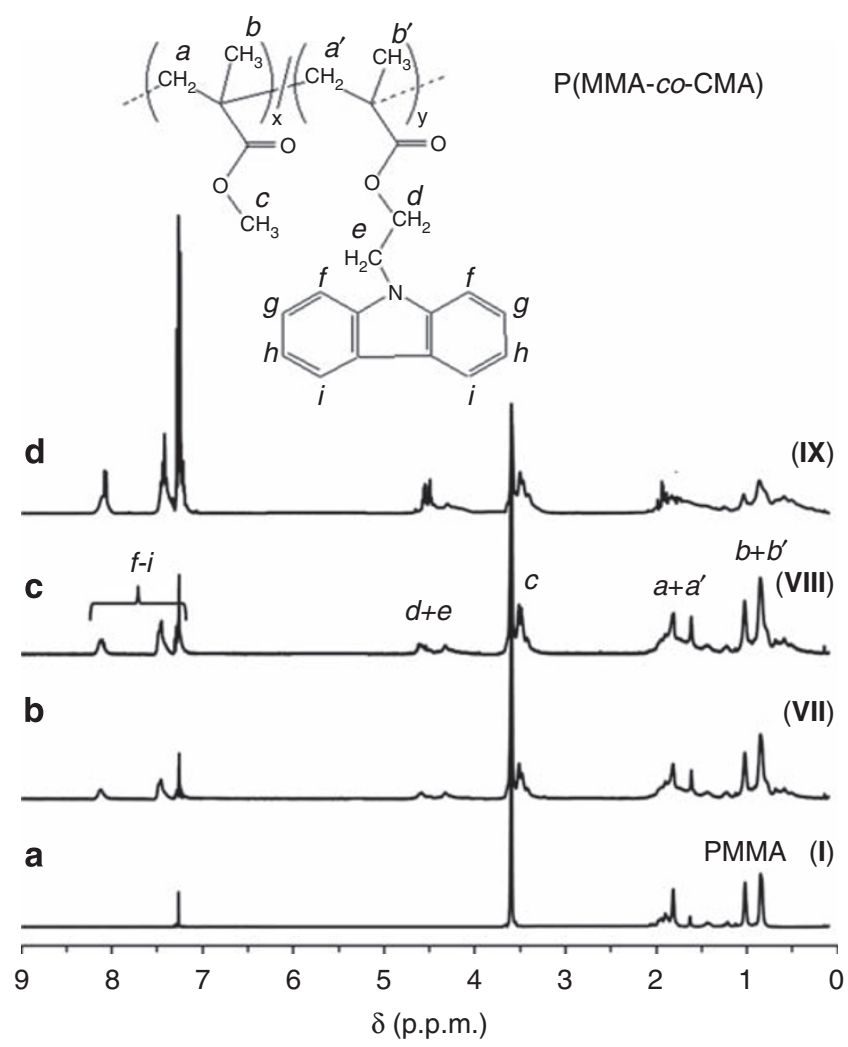

Figure $4{ }^{1} \mathrm{H}$ NMR spectra of (a) PMMA (I) and (b-d) P(MMA-co-CMA) (VII-IX). Conditions are given in Tables 1 and 2. AMA, 9-anthrylmethyl methacrylate; MMA, methyl methacrylate; NMR, nuclear magnetic resonance.

The microstructures of copolymers $\mathrm{P}$ (MMA-co-AMA) and $\mathrm{P}$ (MMA-co-CMA) were confirmed by ${ }^{1} \mathrm{H}$ NMR spectra, as shown in Figures 3 and 4 . The copolymers' compositions were defined by the proportions of units MMA/AMA and MMA/CMA, presented as the parameter $\mathrm{F}_{\mathrm{AMA}}$ in Table 1 and as $\mathrm{F}_{\mathrm{CMA}}$ in Table 2, respectively. In all cases, the resonance signal of $\alpha-\mathrm{CH}_{3}$ protons in the polymethacrylate main chain is divided into three well-resolved peaks at $0.89,1.06$ and 1.24 p.p.m. $\left(b+b^{\prime}\right)$. These peaks are assigned to syndiotactic $(r r)$, heterotactic $(\mathrm{mr}+\mathrm{rm})$ and isotactic $(\mathrm{mm})$ triads. Peaks of narrow shape and high intensity are observed for PMMA (Figures 3a and $4 \mathrm{a})$, but the peaks become broader and less intense with increasing AMA (Figures 3b-e) or CMA (Figures $4 \mathrm{~b}-\mathrm{d}$ ) content in the copolymers. In general, the presence of bulky moieties on both sides of the 
Table 3 Tacticity data for $\alpha$-methyl carbon region of CMA and AMA polymers synthesized by ATRP

\begin{tabular}{lccc}
\hline & $\begin{array}{c}\text { Syndiotactic (rr) } \\
\text { 0.89 p.p.m. }\end{array}$ & $\begin{array}{c}\text { Heterotactic (mr+rm) } \\
\text { 1.06 p.p.m. }\end{array}$ & $\begin{array}{c}\text { Isotactic (mm) } \\
1.24 \text { p.p.m. }\end{array}$ \\
\hline PMMA & 0.57 & 0.38 & 0.05 \\
3.3\% CMA & 0.60 & 0.34 & 0.06 \\
9.5\% CMA & 0.63 & 0.31 & 0.06 \\
18.9\% CMA & 0.66 & 0.26 & 0.08 \\
3.0\% AMA & 0.57 & 0.34 & 0.09 \\
8.8\% AMA & 0.57 & 0.36 & 0.07 \\
15.3\% AMA & 0.62 & 0.33 & 0.05 \\
28.3\% AMA & 0.71 & 0.25 & 0.04 \\
\hline
\end{tabular}

Abbreviations: AMA, 9-anthrylmethyl methacrylate; ATRP, atom transfer radical polymerization; CMA, 2-(9-carbazolyl)ethyl methacrylate; PMMA, poly(methyl methacrylate).

Table 4 Conversion data used for the calculation of the reactivity ratios

\begin{tabular}{lcccccc}
\hline Sample & $M_{1}$ & $\begin{array}{c}f_{1} \text { feed } \\
\text { fraction }\end{array}$ & $\begin{array}{c}F_{1} \text { copolymer } \\
\text { fraction }\end{array}$ & $\begin{array}{c}X_{1} \\
\text { conversion }\end{array}$ & $\begin{array}{c}X_{M M A} \\
\text { conversion }\end{array}$ & $\begin{array}{c}\text { Overall } \\
\text { conversion }\end{array}$ \\
\hline II & AMA & 0.037 & 0.031 & 0.204 & 0.249 & 0.247 \\
III & AMA & 0.105 & 0.086 & 0.180 & 0.224 & 0.219 \\
IV & AMA & 0.187 & 0.149 & 0.158 & 0.207 & 0.198 \\
V & AMA & 0.352 & 0.277 & 0.141 & 0.201 & 0.179 \\
VII & CMA & 0.037 & 0.033 & 0.199 & 0.222 & 0.221 \\
VIII & CMA & 0.105 & 0.094 & 0.142 & 0.160 & 0.158 \\
IX & CMA & 0.210 & 0.187 & 0.125 & 0.144 & 0.140 \\
\hline
\end{tabular}

Abbreviations: AMA, 9-anthrylmethyl methacrylate; CMA, 2-(9-carbazolyl)ethyl methacrylate.

main chain in the case of syndiotactic or heterotactic structures has a strong influence on $\mathrm{CH}_{2}$ protons (1.4-2.0 p.p.m.). Thus, the signals for $-\mathrm{CH}_{2}-$ and $-\mathrm{CH}_{3}$ in the main chain appear as broad multiplets (Figure 3e). The general calculations based on the peak areas of signals, belonging to $\alpha-\mathrm{CH}_{3}$ protons, indicate that all copolymers are mostly syndiotactic, but the value of this fraction decreases with the content of MMA (Table 3). The literature also reports a highly isotactic PCMA being successfully synthesized by anionic polymerization using $t$-butyl magnesium bromide, whereas FRP initiated by $2,2^{\prime}$ azobisisobutyronitrile (AIBN) has resulted in heterotactic PCMA. ${ }^{26}$

The monomer reactivity ratios for the pairs MMA/AMA and MMA/CMA, $r_{\mathrm{MMA}}=1.19, r_{\mathrm{AMA}}=0.48$ and $r_{\mathrm{MMA}}=1.10, r_{\mathrm{CMA}}=0.77$, were estimated graphically according to the Fineman-Ross ${ }^{27}$ procedure with the data in Table 4 . The following equations were used for Figure 5:

$$
G=H r_{1}-r_{2},
$$

where

$$
G=-\left(\frac{f_{1}}{1-f_{1}}\right)\left(\frac{1-2 F_{1}}{F_{1}}\right) \text { and } H=\frac{f_{1}^{2}}{\left(1-f_{1}\right)^{2}} \frac{1-F_{1}}{F_{1}}
$$

Two methacrylate monomers during ATRP usually have comparable values of relative reactivity ratios, such as MMA and $n$-butyl methacrylate $\left(r_{1}=0.98 \text { and } r_{2}=1.26 \text {, respectively }\right)^{28}$ or the methacrylate macromonomers of poly(ethylene oxide) and poly(3-hydroxybutyrate) $\left(r_{1}=0.89\right.$ and $r_{2}=1.12$, respectively). ${ }^{29} \mathrm{~A}$ similar effect was shown for the FRP of the comonomer pair MMA and AMA $\left(r_{1}=1.34\right.$ and $r_{2}=0.92$, respectively); ${ }^{17}$ when $r_{1} \sim r_{2}$, the random composition of the copolymer was postulated. In our studies, a significant difference in

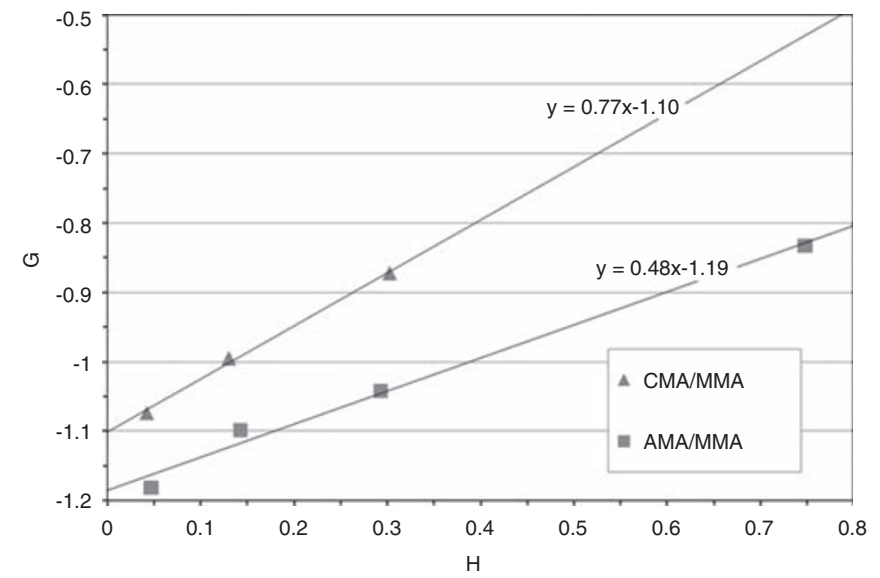

Figure 5 Fineman-Ross plot for the determination of reactivity ratios of MMA/AMA and MMA/CMA comonomer pairs. AMA, 9-anthrylmethyl methacrylate; CMA, 2-(9-carbazolyl)ethyl methacrylate; MMA, methyl methacrylate.

the values of the two reactivity ratios was observed for the methacrylate pair MMA/AMA, indicating that both free radicals, MMA and AMA, easily react with the MMA monomer. Thus, a copolymer formed instantaneously is slightly richer in MMA than the comonomer mixture it originates from. The product $r_{\mathrm{MMA}} r_{\mathrm{CMA}}=0.85$ is closer to unity than $r_{\mathrm{MMA}} r_{\mathrm{AMA}}=0.57$, indicating the reaction system MMA/ CMA leads to a copolymer with a structure closer to random than AMA copolymers.

The DSC thermograms of both types of copolymers are shown in Figure 6. Each polymer sample was amorphous and showed only a single glass transition. Glass transition temperatures $T_{\mathrm{g}} \mathrm{s}$ of the polymers increased with chromophore substituent content, varying between $100^{\circ} \mathrm{C}$ for homopolymer PMMA (I) and $130^{\circ} \mathrm{C}$ for homopolymer PAMA (VI) (Table 1, Figure 6a). A similar dependence was observed for copolymers $\mathrm{P}(\mathrm{MMA}-\mathrm{co}-\mathrm{CMA})$, in which $T_{\mathrm{g}} \mathrm{s}$ changed from $105^{\circ} \mathrm{C}$ (VII) to $125^{\circ} \mathrm{C}$ (IX) with increasing CMA content (Table 2, Figure 6b). Previous studies on the synthesis of PCMA by FRP have reported a $T_{\mathrm{g}}$ of $133^{\circ} \mathrm{C}\left(\mathrm{M}_{\mathrm{n}}=3.3 \mathrm{~kg} \mathrm{~mol}^{-1}, \mathrm{M}_{\mathrm{w}} / \mathrm{M}_{\mathrm{n}}=4.0\right),{ }^{25}$ whereas the copolymerization of MMA and AMA initiated by benzoyl peroxide yielded copolymers with $T_{\mathrm{g}} \mathrm{s}$ in the range from 99.6 to $202.6^{\circ} \mathrm{C} .{ }^{14}$ Our results confirm that the conformational stiffness of the anthryl and carbazolyl groups contributes to the higher $T_{\mathrm{g}}$ of the copolymers in which intermolecular interactions are enhanced, and thus, the mobility of the polymer chains is decreased.

\section{Luminescence properties}

Excitation wavelengths for the studied polymers were defined on the absorption spectra (Figure 7). It was observed that the type of chromophore group did not influence the wavelengths of absorption, which, for all copolymers, are observed in three maxima at 261, 295 and $328 \mathrm{~nm}$. The absorption maximum at $295 \mathrm{~nm}$ is defined as $\lambda_{\text {exc }}$, which was used in further experiments for excitation of the photoluminescence effect in resulting copolymers. The intensity of absorption for the carbazolyl polymer (VII) was twice the value of that for polymers containing the same mol\% of anthryl substituents (II). Moreover, peak intensity increased with the amount of carbazolyl groups attached to the PMMA main chain (from VII to IX).

After being irradiated with a ultraviolet lamp, the spectra of both types of polymers demonstrated three luminescence maxima but at a different range of wavelengths (Figure 8). The methacrylate-based 
a

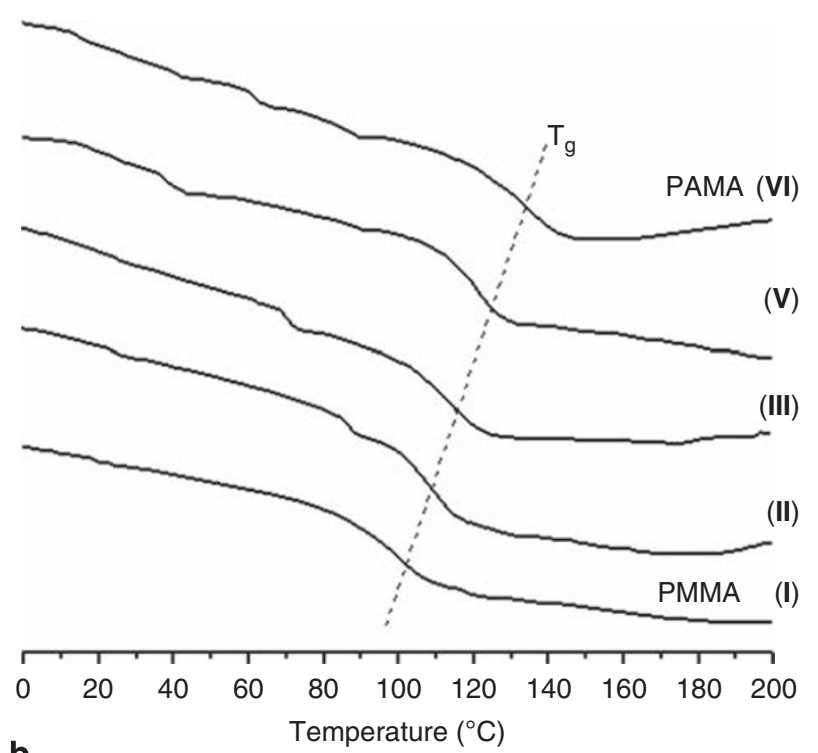

b

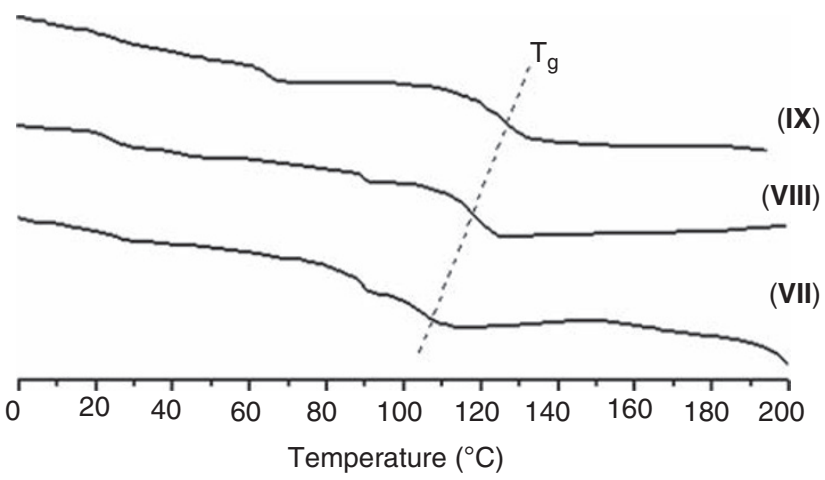

Figure 6 DSC thermograms of (a) (co)polymers of MMA/AMA and (b) MMA/ CMA. Detailed data are given in Tables 1 and 2. AMA, 9-anthrylmethyl methacrylate; CMA, 2-(9-carbazolyl)ethyl methacrylate; DSC, differential scanning calorimetry; MMA, methyl methacrylate.

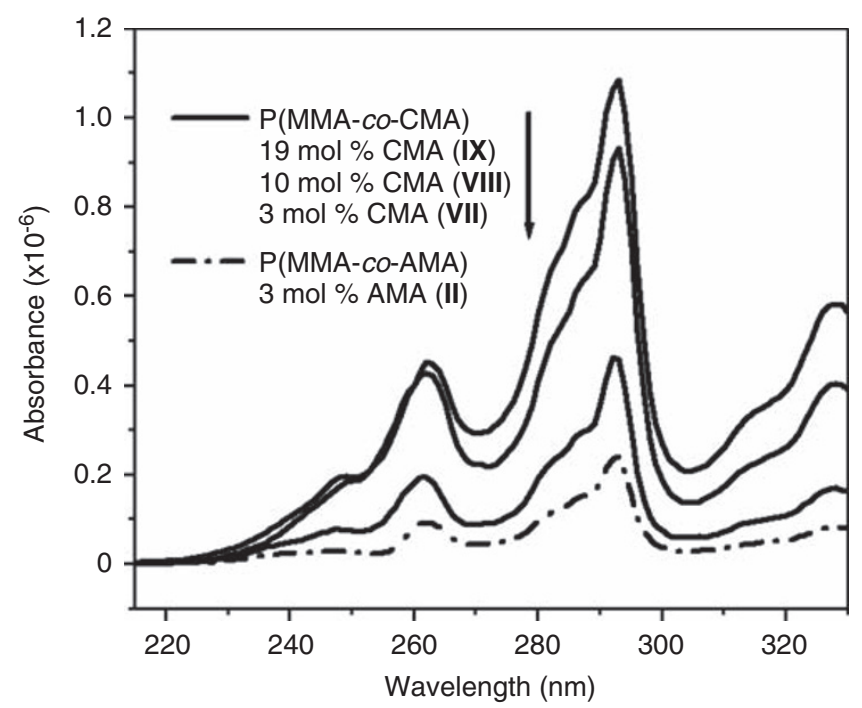

Figure 7 Absorption spectra of copolymers containing carbazolyl (VII-IX) and anthryl groups (II).
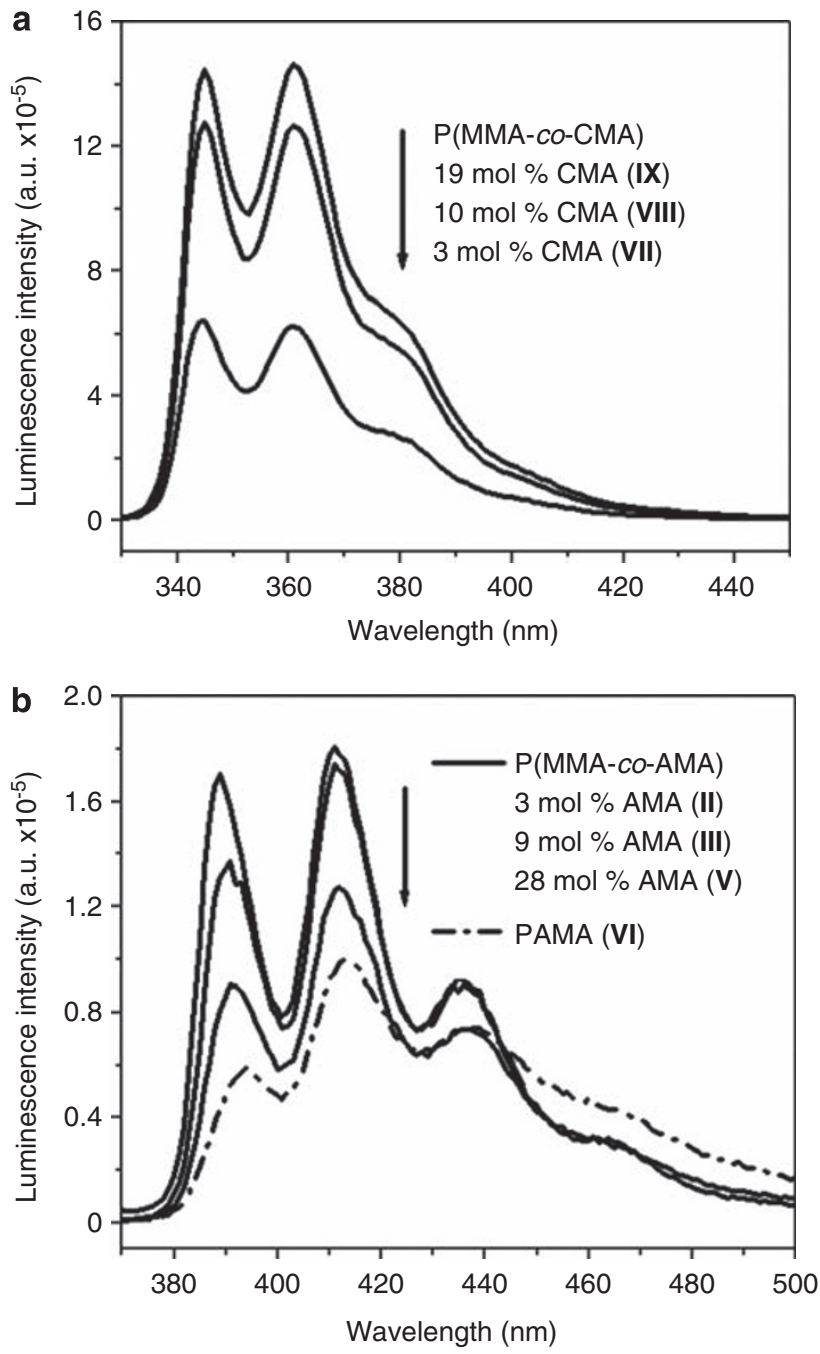

Figure 8 Luminescence spectra of copolymers (a) P(MMA-co-CMA) and (b) $\mathrm{P}(\mathrm{MMA}-\mathrm{Co}-\mathrm{AMA})$ with various contents of chromophore groups. $\lambda_{\text {exc }}=295 \mathrm{~nm}$. AMA, 9-anthrylmethyl methacrylate; CMA, 2-(9-carbazolyl) ethyl methacrylate; MMA, methyl methacrylate.

copolymers with carbazolyl groups had blue-violet fluorescence at 344, 361 and $382 \mathrm{~nm}$, which was observed previously for carbazolylcontaining polyethers prepared by anionic polymerization (352, 368 and $390 \mathrm{~nm}) \cdot{ }^{30}$ In addition, fluorescence maxima at similar wavelengths (348 and $368 \mathrm{~nm}$ using $\lambda_{\mathrm{exc}}=295 \mathrm{~nm}$ ) were present for the copolymers of CMA and methacrylic acid synthesized by uncontrolled FRP. ${ }^{25}$ For anthryl copolymers, light emission was shifted into longer wavelengths in the blue-green range (390, 412 and $438 \mathrm{~nm}$ ), in agreement with the fluorescence results obtained for AMA/MMA copolymers prepared by FRP (maxima at 390, 413 and $442 \mathrm{~nm}$ using $\left.\lambda_{\text {exc }}=350 \mathrm{~nm}\right) .{ }^{17}$

The emission spectra for copolymers containing CMA units (Figure 8a) indicated an initial significant increase in luminescence intensity with increasing CMA concentration in the copolymer (VII and VIII), followed by the change not being particularly large for higher CMA content (IX). An opposite tendency was observed for copolymers with AMA units (Figure 8b), indicating that maximum luminescence was obtained for the copolymer with the lowest content of AMA (II). Light emission by P(MMA-co-AMA) (III-V) and 
P(AMA) (VI) became weaker with an increasing number of anthryl groups. This behavior can be associated with the differential structures of both types of copolymers. The comparison of spectra for copolymers with $3 \mathrm{~mol} \%$ of chromophore groups showed weaker photoluminescence (almost four times lower peak intensity) for P(MMA-co-AMA) (II) than for P(MMA-co-CMA) (VII). A slightly longer spacer between the polymer backbone and the carbazole substituent linked by the nitrogen atom provides an increase in fluorescence intensities of the polymers.

All copolymers exhibited essentially monomeric emission, indicating that the carbazolyl and anthryl groups did not have significant interaction because of the optimally dilute solutions $\left(2 \times 10^{-6} \mathrm{M}\right)$ of a good solvent. The short alkyl spacers are effective for separation of the chromophore substituents from the main chain causing the inhibition of intramolecular excimer formation. ${ }^{31}$ The chains are far apart and in extended conformations, preventing inter- and intra-chromophoric interactions and minimizing energy-transfer processes. However, the band in the spectrum of homopolymer PAMA (Figure 8b) is broader than the bands of the copolymers, suggesting greater conformational disorder. It is likely associated with the steric hindrance of rigid anthryl moieties, which are attached close to the polymer backbone. The band profile maintains a well-resolved vibronic structure, which shows a long tail that extends to high wavelengths.

\section{Conclusions}

The ATRP of MMA, with AMA (4-35 mol\%) or CMA (4-21 mol\%) as the luminescent monomers, was carried out in an organic solvent using an $\mathrm{EtBriBu} / \mathrm{CuBr} / \mathrm{PMDETA}$ system at $70^{\circ} \mathrm{C}$. In contrast to conventional FRP, the well-defined copolymers containing various amounts of chromophore groups, that is, $3-28 \mathrm{~mol} \%$ in $\mathrm{P}(\mathrm{MMA}-\mathrm{co}-$ AMA) and 3-19 mol\% in P(MMA-co-CMA), were obtained. In both cases, polydispersity increased with the content of AMA or CMA units $\left(1.28 \geqslant M_{w} / M_{n} \geqslant 1.53\right)$, but the values were lower for anthryl than for carbazolyl copolymers ( 1.31 vs 1.46 at $10.5 \mathrm{~mol} \%$ of chromophore group content). The relative reactivity ratios for both comonomer pairs, $r_{\mathrm{MMA}}=1.19, r_{\mathrm{AMA}}=0.48$ and $r_{\mathrm{MMA}}=1.10, r_{\mathrm{CMA}}=0.77$, led to the formation of structures between random and gradient spacing of chromophore units along the polymer backbone, depending on the initial feed ratios of the comonomers. The presence of chromophore groups in the resulting copolymers decided their luminescent properties. Both types of copolymers were able to emit light, but with different intensities and ranges of wavelength. Slightly different colors of fluorescence, from blue-violet, with significantly higher intensities (340-380 nm) for the carbazolyl copolymers, to blue-green, with low intensities (390-435 nm) for the anthryl copolymers, were observed. The luminescent polymers with anthryl and carbazolyl groups were amorphous, and thermal analysis indicated an increase in $T_{\mathrm{g}}$ with the content of AMA or CMA units in the copolymers in the range from 100 to $130^{\circ} \mathrm{C}$.

1 Akcelrud, L. Electroluminescent polymers. Prog. Polym. Sci. 28, 875-962 (2003).

2 Gražulevičius, J. V., Strohriegl, P., Pielichowski, J. \& Pielichowski, K. Carbazolecontaining polymers: synthesis, properties and applications. Prog. Polym. Sci. 28, 1297-1353 (2003).

3 Sohn, J., Park, S. Y., Moon, H., Mun, J. \& Yoon, Ch.S. Synthesis and properties of oligomeric poly(glycidyl ether)s with a carbazole-based multifunctional photorefractive chromophore. React. Funct. Polym. 45, 109-117 (2000).
4 Lengvinaite, S., Sangermano, M., Malucelli, G., Priola, A., Grigalevicius, S., Grazulevicius, J. V. \& Getautis, V. Synthesis and cationic photocuring of new carbazole monomers. Eur. Polym. J. 43, 380-387 (2007).

5 Atmaca, L., Kayihan, I. \& Yagci, Y. Photochemically and thermally induced radical promoted cationic polymerization using allyl phosphonium salts. Polymer 41, 60356041 (2000).

6 Lazauskaitè, R. \& Gražulevičius, J. V. Synthesis and cationic photopolymerization of electroactive monomers containing functional groups. Polym. Adv. Technol. 16, 571581 (2005).

7 Budreckiene, R., Lazauskaite, R., Buika, G. \& Gražulevičius, J. V. Cationic photopolymerization of carbazolyl-containing vinyl ethers. J. Photochem. Photobiol. A: Chem. 157, 117-123 (2003).

8 Buika, G., Gražulevičius, J. V., Stolarzewicz, A. \& Grobelny, Z. Anionic polymerization of carbazolyl-substituted oxiranes initiated by potassium alkalide, potassium tert-butoxide and potassium hydride. Macromol. Chem. Phys. 196, 1287-1293 (1995).

9 Cho, Y- S., Lee, J- S. \& Cho, G. Anionic polymerization of 2-(N-carbazolyl)ethyl methacrylate. Polymer 43, 1197-1202 (2002).

10 Lyoo, W. S. Synthesis of ultrahigh molecular weight poly( $N$-vinylcarbazole) with a high yield using low-temperature heterogeneous-solution polymerization. J. Polym. Sci. Part A: Polym. Chem. 39, 539-545 (2001).

11 Makowska-Janusik, M., Sanetra, J., Palmer, H., Bogdał, D., Gondek, E. \& Kityk, I. V. Absorption spectra of poly- $N$-vinylcarbazole derivatives by experiment and simulation. Eur. Polym. J. 40, 799-804 (2004).

12 Keyanpour-Rad, M., Ledwith, A., Hallam, A., North, A. M., Breton, M., Hoyle, C. \& Guillet, J. E. Some photophysical properties of five new carbazole-containing methacrylate polymers. Macromolecules 11, 1114-1118 (1978).

13 Keyanpour-Rad, M., Ledwith, A. \& Johnson, G. E. Synthesis and emission properties of poly( $N$-ethyl-4-vinylcarbazole). Macromolecules 11, 222-229 (1980).

14 Bratschkov, Ch. FTIR spectroscopy study of the UV irradiation induced changes in an anthracene containing copolymer. Eur. Polym. J. 37, 1145 (2001).

15 Bratschkov, Ch., Karpuzova, P., Müllen, K., Klapper, M. \& Schopov, I. Synthesis and photochemical transformations of an anthracene containing methacrylic copolymer. Polym. Bull. 46, 345-349 (2001).

16 Ferreira de Deus, J., Tavares, A. C., Lepienski, C. M. \& Akcelrud, L. Nanomechanical properties of poly(methyl methacrylate-co-9-anthryl methyl methacrylate). Surf. Coat. Technol. 201, 3615 (2006).

17 Ferreira de Deus, J., Andrade, M. L., Atvars, T. D. Z. \& Akcelrud, L. Photo and electroluminescence studies of poly(methyl methacrylate-co-9-anthryl methyl methacrylate). Chem. Phys. 297, 177-186 (2004).

18 Matyjaszewski, K. \& Xia, J. Atom transfer radical polymerization. Chem. Rev. 101, 2921-2990 (2001).

19 Kamigaito, M., Ando, T. \& Sawamoto, M. Metal-catalyzed living radical polymerization. Chem. Rev. 101, 3689-3745 (2001).

20 Moon, B., Hoye, T. R. \& Macosko, C. W. Synthesis and application of fluorescently labeled phthalic anhydride (PA) functionalized polymers by ATRP. Polymer 43, 55015509 (2002).

21 Kim, C. S., Oh, S. M., Kim, S. \& Cho, C. G. Preparation of anthracene-labelled poly(methyl methacrylate) via atom transfer radical polymerization. Macromol. Rapid Commun. 19, 191-196 (1998).

22 Ohno, K., Fujimoto, K., Tsujii, Y. \& Fukuda, T. Synthesis of a well-defined anthracenelabelled polystyrene by atom transfer radical polymerization. Polymer 40, 759-763 (1999).

23 Tong, J.- D., Zhou, C., Ni, S. \& Winnik, M. A. Synthesis of meth(acrylate) diblock copolymers bearing a fluorescent dye at the junction using a hydroxyl-protected initiator and the combination of anionic polymerization and controlled radical polymerization. Macromolecules 34, 696-705 (2001).

24 Strohriegl, P. A novel synthesis of polyacrylates and polymethacrylates with pendant carbazole groups. Mol. Cryst. Liq. Cryst. 183, 261-267 (1990).

25 Rutkaite, R., Buika, G. \& Gražulevičius, J. V. Synthesis and characterization of copolymers of carbazolylalkyl(meth)acrylates and methacrylic acid. Polym. Bull. 46, 59-66 (2001).

26 Brar, A. S. \& Markanday, M. Analytical evaluation of stereoregularity in poly(2- $N$ carbazolylethyl methacrylate) by two-dimensional NMR spectroscopy. React. Funct. Polym. 66, 537-550 (2006).

27 Fineman, M. \& Ross, S. D. Linear method for determining monomer reactivity ratios in copolymerization. J. Polym. Sci. 5, 259-265 (1950).

28 Haddleton, D. M., Crossman, M. C., Hunt, K. H., Topping, C., Waterson, C. \& Suddaby, K. G. Identifying the nature of the active species in the polymerization of methacrylates: inhibition of methyl methacrylate homopolymerizations and reactivity ratios for copolymerization of methyl methacrylate/ $n$-butyl methacrylate in classical anionic, alkyllithium/trialkylaluminum- initiated, group transfer polymerization, atom transfer radical polymerization, catalytic chain transfer, and classical free radical polymerization. Macromolecules 30, 3992-3998 (1997).

29 Neugebauer, D., Rydz, J., Goebel, I., Dacko, P. \& Kowalczuk, M. Synthesis of graft copolymers containing biodegradable poly(3-hydroxybutyrate) chains. Macromolecules 40, 1767-1773 (2007)

30 Pisarski, W. A., Swinarew, A. S., Czaja, M., Piekarnik, B., Grobelny, Z., Getautis, V., Gražulevičius, J. V., Niedziela, T., Trzebicka, B. \& Stolarzewicz, A. Optically induced carbazolyl containing polyethers: concentration effect. J. Mol. Struct. 887, 205-208 (2008).

31 Ledwith, A., Rawley, N. J. \& Walker, S. M. Fluorescence emission from poly[2-(9ethyl)carbazolyl-methylmethacrylate]. Polymer 22, 435-436 (1981). 